\title{
Stimulation of hamster and human lymphocyte cultures by soluble egg antigens (SEA) of Schistosoma haematobium and S. mansoni*
}

\author{
N. Weiss, U. P. Oberlin and A. Degrémont \\ Swiss Tropical Institute, Basle, Switzerland
}

\section{Summary}

Soluble egg and adult worm antigen preparations of Schistosoma haematobium and S. mansoni were tested in hamster and human lymphocyte cultures. Primed lymphocytes from infected donors showed a marked blastogenic response to the homologous antigens. A cross-reactivity to the heterologous antigens was seen especially in $S$. mansoni infected hamsters.

\section{Introduction}

The role of soluble egg antigens (SEA) in the aetiology of liver granuloma formation in schistosomiasis is well known (reviewed by WARREN, 1972). A cell-mediated immune response occurs around viable eggs secreting SEA or around bentonite particles coated with SEA. Furthermore SEA induce and elicit delayed hypersensitivity reactions in guinea-pigs as manifested by dermal reactivity, lymphocyte transformation and macrom phage migration inhibition (Boros et al, 1973). Lymphocyte blastogenesis and macrophage migration inhibition were also studied in mice in the course of Schistasoma mansoni infections (COLLEY, 1972; Boros et al, 1975). Both in vitro assays are in good correlation with the granulomatous reaction seen in vivo, so that in late (chronic) infections a decline of the responsiveness in vitro goes parallel to the decreasing granulomatous response. Whether antibodies to SFA detected at this time may modulate the cellular response was recently discussed (Boros et al, 1975).

Fxperimental schistosomiasis has been less studied in hamsters, although this animal is a suitable host for all human schistosome species (ERICKSON et al, 1974).

Our preliminary results with hamster and human lymphocytes are part of a comparative study on $S$. haematobium and $S$. mansoni infections. In order to analyse the specificity of the cell-mediated immune response to homologous and heterologous schistosome antigen preparations, an in vitro assay for lymphocyte transformation has been designed.

Materials and methods
Experimeniul infection of Syrian hamsters
Male hamsters ( $60 \mathrm{~g}$ body weight) were infected with
100 or 300 cercariae of $S$. haematobium (strain isolated in
Madagascar and maintained in Bulinus obtusispira) by
paddling in a cercarial suspension, or by subcutaneous
infection of 100 cercariae of $S$. mansoni (strain isolated in
Liberia and maintaincd in Biomphalaria glabrata).
Antigen preparation
Eggs were collected by tryptic digestion of liver tissue
obtained from hamsters infected with $S$. haematobium
(about 16 weeks p.inf.) or with $S$. mansoni (8-9 weeks
p.inf.) and purified by several filtration steps (BRown
and THOMss, 1963). The eggs were homogenized in

* Supported by a grant of the Schweizerischer Nationalfonds (Nr. 3.2900.74). medium RPMI 1640 (Flow) with a glass tissue homogenizer. After centrifugation the supernatant (soluble egg antigens, SEA) was sterilized by filtration (Millipore $0.22 \mu$ ) and stored at $-70^{\circ}$ in small aliquots (Boros and WARREN, 1970). Delipidized adult schistosome antigens (SAA) were prepared essentially as described by CHAFFEE et al (1954). A buffered saline extract of ether-extracted adult schistosomes was dialysed against medium RPMI 1640 , filter-sterilized and stored in small aliquots at $-70^{\circ} \mathrm{C}$. Protein concentrations were determined according to LoWRY et al (1951).

Cell suspension and culture conditions

Lymphocytes from hamsters were obtained by teasing lymph nodes. The cell suspension was filtered through glasswool. After two washes in Hanks (Flow) the cells were transferred in medium RPMI 1640 supplemented with Hepes (Flow, 0.03M), penicillin (Difco, $100 \mathrm{U} / \mathrm{ml}$ ), streptomycin (Difco, $100 \mu \mathrm{g} / \mathrm{ml}$ ), fresh l-glutamine (Flow, $20 \mathrm{mM}$ ) and $2.5 \%$ heat inactivated normal hamster serum (MEO, T., 1974, personal communication). Human lymphocytes were obtained from heparinized peripheral blood by density gradient centrifugation (Ficoll-Urografin $\mathrm{d}=1.077$ ) as described by BøYUM (1968). The culture medium was the same as described above but included $10 \%$ inactivated human $A B$ serum instead of hamster serum. The cells were cultured in round-bottomed tissue culture microplates (Cooke). The best results were obtained with a cell concentration of $2 \times 10^{6}$ viable hamster cells and $10^{6}$ human lymphocytes per $\mathrm{ml}$ respectively.

The cultures were set up in quadruplicates $(200 \mu 1$ total volume per well) with various doses of SEA or SAA, without antigen and with a non-specific mitogen (PHA M, Difco) at a final dilution of $1 \%$. The cultures were incubated at $37^{\circ} \mathrm{C}$ in a humid atmosphere of $5 \%$ $\mathrm{CO}_{2}$ in air. The cultures were pulsed with $2 \mu \mathrm{Ci}$ per well of $3 \mathrm{H}$-thymidine (NEN, specific activity $20 \mathrm{Ci} / \mathrm{mM}$ ) at day 4 for 24 hours.

Cell harvesting and counting

The cells were collected from the culture wells on to glass fibre filters with a cell harvesting apparatus (Skatron), dried at $60^{\circ} \mathrm{C}$ and solubilized by adding $100 \mu \mathrm{l}$ of hyamine-hydroxide (Calbiochem) per filter. The samples were counted after addition of $10 \mathrm{ml}$ of scintillation fluid (Permablend III, Packard) in a liquid scintillation counter.

The degree of response is expressed in net $\mathrm{cpm}(=\mathrm{cpm}$ of stimulated cultures minus cpm of unstimulated cultures) and reported as mean \pm standard error (s.e.). 

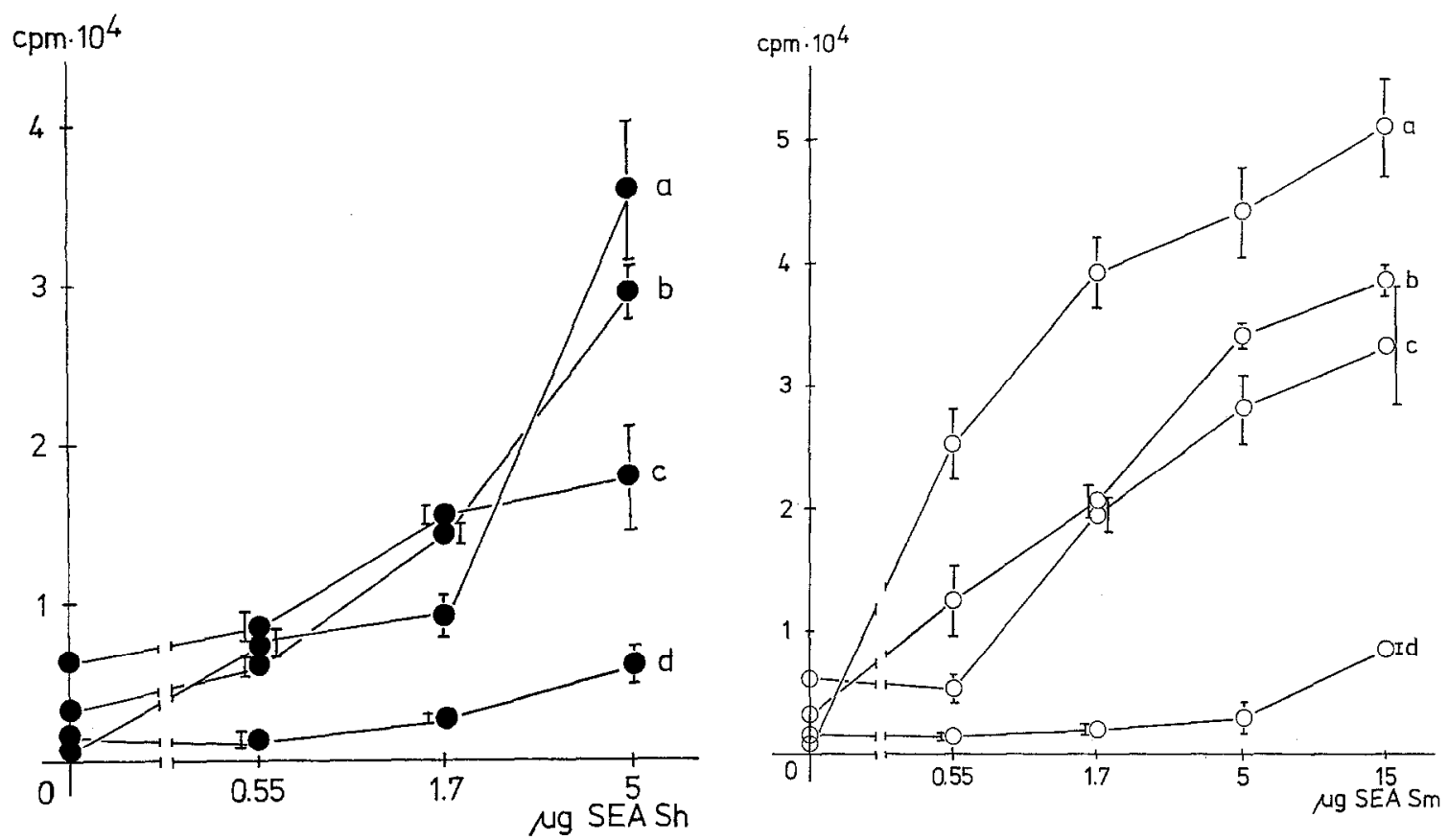

Fig. 1. Dose response curve for $S$. haematobium-infected hamsters ( $a=300$ cercariae, 16 weeks post inf., $b=100$ cercariae, 23 weeks post inf.). Stimulation by homologous SEA (open circles) and heterologous SEA (closed circles).

\section{Results}

Hamster lymphocyte cultures

A marked blast transformation can be induced in vitro by SEA in lymphocytes from hamsters in which schistosome egg production has started. The effect of various antigen concentrations on the blastogenic response of $S$. haematobium infected hamsters is shown in Fig. 1. A maximal response to the homologous SEA is observed at an antigen dose of $5 \mu \mathrm{g}$ protein per culture. With the same concentrations of heterologous SEA no stimulation was detectable. The blastogenic response of lymphocytes from hamsters infected with $S$. mansoni gets higher with increasing amounts of homologous and heterologous antigens (Fig. 2). At a given antigen concentration the stimulation was higher with the homologous SEA.

Lymphocytes from uninfected hamsters were also stimulated by antigen doses exceeding $5 \mu \mathrm{g}$ protein per culture. In preliminary experiments the blastogenicity of delipidized, soluble adult schistosome antigens (SAA) was compared to that of SEA (Table I). SAA-Sh* was less stimulatory than SEA-Sh. Despite a high stimulation of unprimed lymphocytes a significant response $(\mathrm{P}=<0.005)$ was observed with cells from hamsters infected with $S$. haematobium. Both antigens derived from S. haematobium and SEA-Sm showed a significantly higher stimulation in the homologous system. The difference in stimulation between adult and egg antigens of $S$. mansoni was less pronounced than between the Sh antigens. The results of lymphocyte transformation experiments using hamsters infected either with $S$. haematobium or $S$. mansoni are listed in Table II. The mean response of lymphocytes primed in a $S$. haematobium infection to the homologous SEA was $5 \cdot 2$ times higher than that to the heterologous antigens. The difference in stimulation was highly significant $\left(26^{\prime} 562+\right.$ $4^{\prime} 764 \mathrm{cpm} ; \mathrm{P}=<0.005$ ).

*SAA-Sh: soluble adult worm antigens of S. haematobium

Table I - Blastogenicity of different antigens (protein concentration $5 \mu \mathrm{g} /$ culture) in hamster lymphocyte cultures (SEA: soluble egg antigens, SAA: soluble adult antigens)

\begin{tabular}{|c|c|c|c|c|c|}
\hline \multirow{2}{*}{$\begin{array}{l}\text { Hamsters } \\
\text { infected with }\end{array}$} & \multirow{2}{*}{$\begin{array}{c}\text { cpm of } \\
\text { unstimulated } \\
\text { cultures } \\
\text { (mean } \pm \text { s.e.) }\end{array}$} & \multicolumn{4}{|c|}{ net cpm (mean士s.e.) ${ }^{1}$} \\
\hline & & SEA Sh & SAA Sh & SEA Sm & SAA Sm \\
\hline $\begin{array}{l}\text { S. haematobium } \\
\text { S. mansoni } \\
\text { uninfected control }\end{array}$ & $\begin{array}{r}2,607 \pm 758 \\
2,874 \pm 756 \\
830 \pm 234\end{array}$ & $\begin{array}{c}32,883 \pm 5,239 * \\
13,807 \pm 4,705^{*} \\
2,255 \pm 967\end{array}$ & $\begin{array}{c}14,644 \pm 2,227 \dagger \\
2,357 \pm 3,394 \dagger \\
4,518 \pm 415\end{array}$ & $\begin{array}{c}6,321 \pm 2,923^{*} \\
19,888 \pm 5,187^{*} \\
1,099 \pm 344\end{array}$ & $\begin{array}{c}\text { n.d. } \\
14,620 \pm 3,518 \\
1,167 \pm \quad 155\end{array}$ \\
\hline
\end{tabular}


Table II - Lymphocyte transformation induced by SEA ( $5 \mu \mathrm{g}$ protein/culture) in individual hamsters infected with $S$. haematobium or $S$. mansoni

\begin{tabular}{|c|c|c|c|}
\hline $\begin{array}{l}\text { Hamsters } \\
\text { infected with }\end{array}$ & $\begin{array}{c}\text { SEA Sm } \\
\text { net } \mathrm{cpm}^{1} \\
\text { (mean } \pm \text { s.e.) }\end{array}$ & $\begin{array}{c}\text { SEA Sh } \\
\text { net cpm } \\
\text { (mean } \pm \text { s.e.) }\end{array}$ & $\begin{array}{c}\text { Difference } \\
\text { in stimulation }{ }^{2} \\
\text { cpm }\end{array}$ \\
\hline \multicolumn{4}{|c|}{ S. haematobium } \\
\hline $\mathrm{Cc}^{3} \quad \mathrm{wk}^{4}$ & & & \\
\hline $100 \quad 23$ & $-88 \pm \quad 48$ & $23,706 \pm 2,313$ & 23,794 \\
\hline 100 & $14,269 \pm 4,465$ & $54,086 \pm 1,842$ & 39,817 \\
\hline 300 & $188 \pm \quad 68$ & $24,778 \pm 915$ & 24,590 \\
\hline 300 & $-372 \pm \quad 70$ & $41,615 \pm 3,267$ & 41,987 \\
\hline 300 & $12,566 \pm 1,401$ & $16,367 \pm 1,893$ & 3,801 \\
\hline 300 & $16,605 \pm 1,868$ & $44,734 \pm 6,926$ & 28,129 \\
\hline 300 & $1,079 \pm 216$ & $24,898 \pm 3,247$ & 23,819 \\
\hline mean \pm s.e. & $6,321 \pm 2,923$ & $32,883 \pm 5,239$ & $26,562 \pm 4,764$ \\
\hline
\end{tabular}

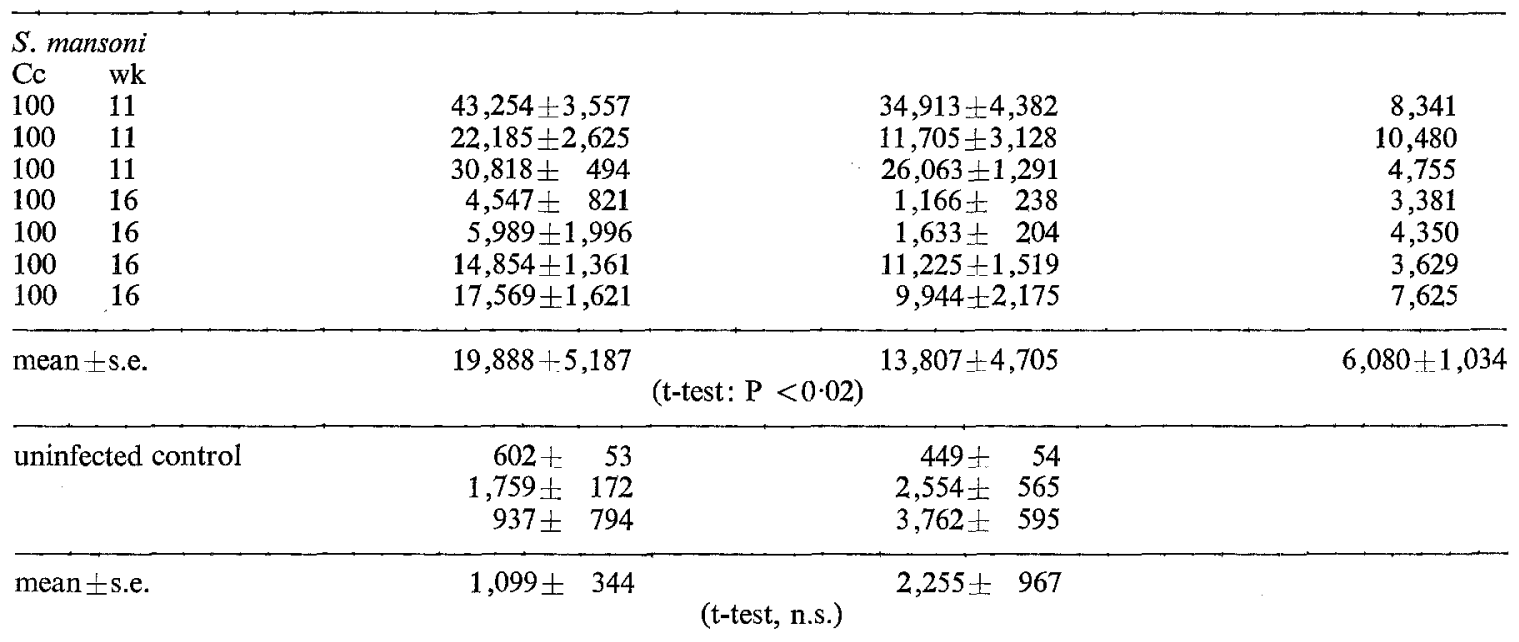

${ }^{1}$ net $\mathrm{cpm}=\mathrm{cpm}$ of stimulated cultures $-\mathrm{cpm}$ of unstimulated cultures.

${ }^{2}$ Difference in stimulation $=$ net $\mathrm{cpm}$ (homologous antigen) - net $\mathrm{cpm}$ (heterologous antigen).

${ }^{3} \mathrm{Cc}=$ number of cercariae per animal.

${ }^{4} \mathrm{wk}=$ weeks post infection.

Table III - Lymphocyte transformation induced by SEA ( $5 \mu \mathrm{g}$ protein/culture) in patients infected with $S$. haematobilum or S. mansoni

\begin{tabular}{|c|c|c|c|c|}
\hline Patient & $\begin{array}{c}\text { cpm of } \\
\text { unstimulated } \\
\text { cultures } \\
\text { (mean } \pm \text { s.e.) }\end{array}$ & $\begin{array}{c}\text { SEA Sm } \\
\text { net } \mathrm{cpm}^{1} \pm \text { s.e. }\end{array}$ & $\begin{array}{c}\text { SEA Sh } \\
\text { net } \mathrm{cpm} \pm \mathrm{s} . \mathrm{e}\end{array}$ & $\begin{array}{c}\text { Difference } \\
\text { in } \\
\text { stimulation }^{2} \\
\text { cpm }\end{array}$ \\
\hline $\begin{array}{l}\text { A.D. (Sh) } \\
\text { A.R. (Sm) } \\
\text { N.N. (control) }\end{array}$ & $\begin{array}{r}1,527 \pm 69 \\
1,252 \pm 114 \\
788 \pm 25\end{array}$ & $\begin{array}{r}11,871 \pm 664^{*} \\
6,582 \pm 211 \dagger \\
997 \pm 285 \ddagger\end{array}$ & $\begin{array}{r}13,252 \pm 598^{*} \\
809 \pm 122 \dagger \\
289 \pm 39 \ddagger\end{array}$ & $\begin{array}{l}1,381 \\
5,773\end{array}$ \\
\hline
\end{tabular}

${ }^{1}$ and ${ }^{2}$ : sec Table II.

* t-test n.s.

$\uparrow$ t-test: $\mathrm{P}<0.001$.

$\ddagger$ t-test: $P<0.025$. 


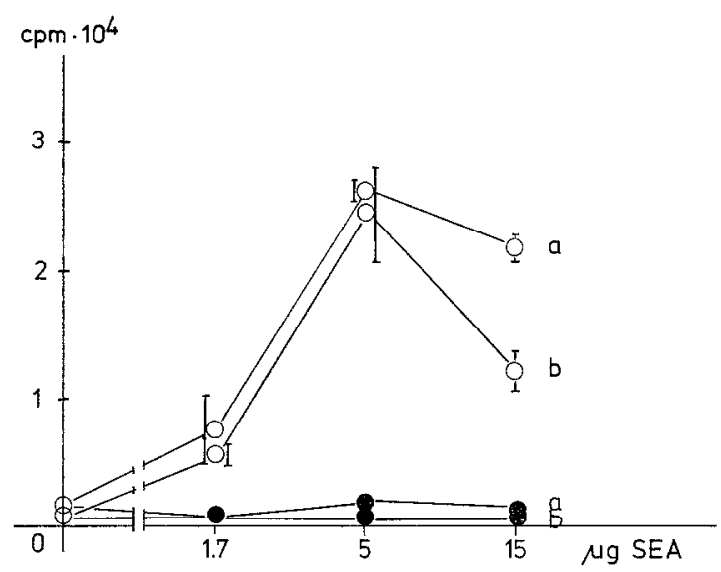

Fig. 2. Dose response curve for $S$. mansoni-infected hamsters ( $a, b, c=100$ cercariae, 11 weeks post inf.) and an uninfected hamster (d). Stimulation by homologous SEA (open circles) and heterologous SEA (closed circles).

In contrast in the $S$. mansoni infected hamsters the ratio between homologous and heterologous SEA was only 1.4 and the difference in stimulation was low (6.080 $\pm 1^{\prime} 034 \mathrm{cpm}, P=<0 \cdot 02$ ). The two antigens innuced a weak primary response of unprimed lymphocytes.

Preliminary experiments were also performed with human lymphocytes (Table III). In this experiment two patients and one uninfected donor were examined. A.D. had a reinfection with $S$. haematobium 20 months ago and eggs were found in the urine. His lymphocytes showed a highly significant blastogenic response compared to the uninfected donor but there was no significant difference between the two SEA tested. A.R. was lightly infected with $S$. mansoni for more than 16 months (stool examinations were negative; a few eggs were found in a rectal biopsy specimen). In this case the stimulation induced by the homologous SEA was significantly higher as compared to the heterologous SEA.

\section{Discussion}

A blast transformation of lymphocytes originating from $S$. haematobium and $S$. mansoni infected hamsters was induced in vitro by soluble antigens prepared from eggs and adult worms of both Schistosoma species. The response of lymphocytes to homologous SAA and SEA was consistently higher than the response to the corresponding heterologous antigen. The blastogenicity induced by SAA is lower than to SEA. Whether the reaction to SAA is due to common antigens of adult worms and eggs (as demonstrated by SADUN et al, 1965) or whether, in addition, stage specific adult blastogens are involved has to be clarified. The species specificity of these antigens is not absolute since primed lymphocytes reacted also with the heterologous antigen. Gel diffusion analyses have demonstrated a close antigenic relationship between these two schistosome specics (CAProv et al, 1966). Our results indicate that not only the humoral but also the cell-mediated immune response to the two schistosome antigens shows some cross-reactivity, especially when lymphocytes were sensitized in an active infection by $S$. mansoni. Lymphocytes from $S$. haematobium-infected hamsters showed none or only a moderate cross reactivity.
WARREN and DOMINGo (1970) studied the granulomatous reaction elicited by intravenous injection of eggs into sensitized mice. As in our experiments the cross-reactivity was prominent in $S$. mansoni-sensitized mice challenged with $S$. haematobium eggs. It has already been demonstrated that the duration and the severity of murine schistosomiasis mansoni has an influence on the cellmediated immune response (COLleY, 1972; Boros et al, 1975). In order to evaluate these effects studies on the kinetics of the blastogenic response of hamsters infected lightly or heavily with $S$. haematobium and $S$. mansoni are under way. Furthermore purified egg antigens will be used to study the specificity of lymphocyte blastogenesis.

In conclusion we can say that the hamster, which is a suitable host for human schistosome species, is an adequate model for a comparative study of the cellmediated immune response to schistosomes.

\section{Acknowledgement}

The technical assistance of Mrs. K. Schläppi is gratefully acknowledged.

\section{References}

Boros, D. L. \& Warren, K. S. (1970). Delayed hypersensitivity-type granuloma formation and dermal reaction induced and elicited by a soluble factor isolated from Schistosoma mansoni eggs. Journal of Experimental Medicine, 132, 488-507.

Boros, D. L., Schwartz, H. J., Powell, A. E. \& Warren, K. S. (1973). Delayed hypersensitivity, as manifested by granuloma formation, dermal reactivity, macrophage migration inhibition and lymphocyte transformation, induced and elicited in guinea pigs with soluble antigens of Schistosoma mansoni eggs. Journal of Immunology, 110, 1118-1125.

Boros, D. L., Pelley, R. P. \& Warren, K. S. (1975). Spontaneous modulation of granulomatous hypersensitivity in schistosomiasis mansoni. Journal of Immunology, 114, 1437-1441.

Bøyum, A. (1968). Separation of leucocytes from blood and bone marrow. Scandinavian Journal of Clinical and Laboratory Investigation, 21, 1-109.

Browne, H. G. \& Thomas, J. I. (1953). A method for isolating pure, viable schistosome eggs from host tissues. Journal of Parasitology, 49, 371-374.

Capron, A., Vernes, A., Biguet, S. \& Rose, F. (1966). Les précipitines sériques dans les bilharzioses humaines et expérimentales à Schistosoma mansont, S. haematobium et S. japonicum. Annales de Parasitologie Humaine et Comparée, 41, 123-187.

Chaffee, E. F., Bauman, P. H. \& Shapilo, S. S. (1954). Diagnosis of schistosomiasis by complement fixation. American Journal of Tropical Medicine and Hygiene, 3, 905-913.

Colley, D. G. (1972). Schistosoma mansoni: eosinophilia and the development of lymphocyte blastogenesis in response to soluble cgg antigen in inbred mice. Experimental Parasitology, 32, 520-526.

Erickson, D. G., Jones, C. E. \& Tang, D. B. (1974). Schistosomiasis in hamsters: the relationship of egg concentration in the liver to disease. American Journal of Tropical Medicine and Hygiene, 23, 449-463.

Lowry, O. H., Rosebrough, N. J., Farr, A. L. \& Randall, R. J. (1951). Protein measurement with the folin phenol reagent. Journal of Biological Chemistry, 193, 265-275. 
Sadun, E. H., Schoenbechler, M. J. \& Bentz, M. (1965). The multiple antibody response in Schistosoma mansoni infections. Antigenic constituents in eggs, cercariae and adults (excretions and secretions) determined by flocculation reactions, cross absorption and double diffusion studies. American Journal of Tropical Medicine and Hygiene, 14, 977-995.
Warren, K. S. (1972). The immunopathogenesis of schistosomiasis: a multi-disciplinary approach. Transactions of the Royal Society of Tropical Medicine and Hygiene, 66, 417-432.

Warren, K. S. \& Domingo, E. O. (1970). Granuloma formation around Schistosoma mansoni, S. haematobium. and S. japonicum eggs. American Journal of Tropical Medicine and Hygiene, 19, 292-304.

\section{Book Review}

Cheebrough, M. \& McArthur, J. (1976), A, laboratory manual for rural tropical hospitals. $A$ basis for training courses. Edinburgh, U.K.: Churchill Livingstone, xxiii + 209 pp. (ISBN 0-443-01144-3. £2-50.)

In tropical developing countries the concept of community health is of great importance; communicable diseases constitute the bulk of medical practice but these can only be reliably diagnosed in laboratories. The publication of a manual, written by two authors with considerable experience in the field and aimed at training laboratory technicians, is welcome and will contribute greatly to improving standards in community health and in diagnosis in rural tropical hospitals.

The manual is divided into seven main sections: laboratory equipment; microscopy; haematology; blood transfusion; bacteriology; examination of stools, urine and other fluids; parasitology. In addition there are 11 pages of definitions of words used in the manual as well as an appendix of three pages in which instructions on preparing solutions and other practical information are included. The alphabetical index of nine pages makes the search for any information simple. The manual is well illustrated by clear line drawings and high quality photographs which enhance the clarity of the text and hence its practical usefulness. In the back cover of the manual there is a novel introduction: this is the inclusion of two strips of film with 16 colour transparencies and a collapsible viewer. The transparencies represent blood films of various types and some of the organisms to which reference is made as they appear under the microscope and are of very high quality. The generous spacing, the double column layout, the clarity of printing and the binding add to the value of the manual for daily practical use.

Most of the techniques employed in laboratories are covered and most of the organisms likely to be found in tropical countries are included. This manual should assist in the formation of reliable medical laboratory services in tropical rural areas and should create in laboratory workers an awareness of their opportunities and responsibilities. The authors have drawn widely on their own considerable practical experience and have certainly achieved their aim to produce a handbook of value to laboratory technicians and doctors working in rural areas. The remarkably low price of $£ 2.50$, made possible through financial assistance from several organizations, puts it within the reach of all for whom it is intended. It should not only be on the bench in all rural tropical hospitals hut also in those departments and hospitals concerned in the training of those about to go to these areas.

L. F. KHALII 